\title{
Christine Anne Cunegonde Wijman, MD, PhD (1965-2013)
}

\author{
Anna Finley Caulfield · Chitra Venkatasubramanian
}

Published online: 21 May 2013

(C) Springer Science+Business Media New York 2013

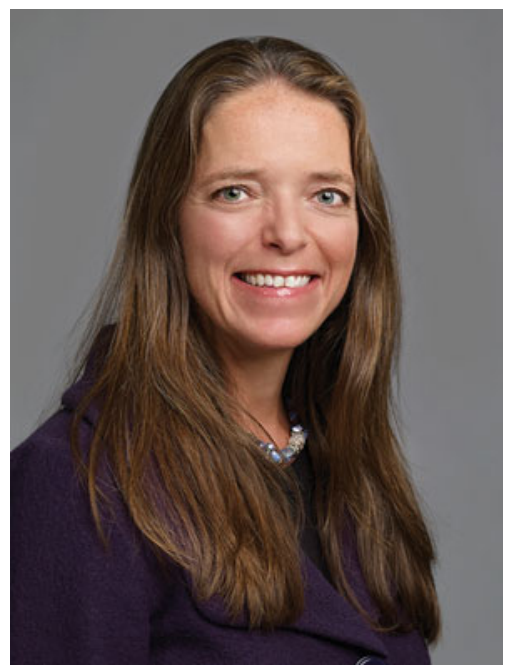

Cristanne (Christine Anne Cunegonde) Wijman, MD, PhD, director of neurocritical care at Stanford University School of Medicine, died unexpectedly on Feb 28, 2013. She was 47 years old. She was a brilliant researcher, superb clinician, and a dedicated teacher, who founded Stanford's neurocritical care program and tirelessly worked to improve the care of patients with critical neurological illnesses. With her infectious enthusiasm for work and all that life had to offer, she touched the lives of her patients, trainees, and her colleagues.

Born in Amsterdam to a medical family (her father was an obstetrician and her mother a nurse), she completed her medical degree from the University of Leiden, the Netherlands (1992). A perpetual love for adventure led her from

A. Finley Caulfield $(\square) \cdot C$. Venkatasubramanian Stanford University School of Medicine, Stanford, CA, USA e-mail: afinley@stanford.edu

her homeland to Boston University School of Medicine where she completed her residency and a cerebrovascular fellowship (1993-1998). Dr. Carlos Kase, chief of neurology at BUMC, noted that she was "one of our favorite trainees of all time" and that she had a "clear intelligence and a drive to succeed." She subsequently trained in neurocritical care at Johns Hopkins University Hospital and then returned to the University Medical Center, Utrecht as a staff neurologist. In 2001, she was recruited by Stanford University to establish a neurocritical care program. Dr. Ann Weinacker, intensivist and chief of staff at Stanford recalled, "Cristanne helped us realize how much could be done for patients with devastating strokes and neurological illnesses."

Cristanne received her doctorate of philosophy in 2007 from the University Medical Center, Utrecht for her work on "Retinal Ischemia and Embolism-Causes and Outcomes." Her research at Stanford was focused on advanced MR imaging and biomarkers in predicting outcomes of comatose survivors of cardiac arrest and assessing the diagnostic utility of MRI in intracerebral hemorrhage. For these projects, she received funding from the American Heart Association and the National Institute of Health. She authored 75 peer-reviewed papers and 120 abstracts. She was a principle investigator on numerous multi-center clinical trials. She was a board member of the Neurocritical Care Society and an organizing member for the first Neurocritical Care Research Conference.

Cristanne established Stanford's Neuro-Outcomes clinic, which has been used not only to assess long-term outcomes in post-ICU patients but also to teach trainees to incorporate this knowledge when advising families in crisis in the intensive care unit. As a clinician, her patients and their families loved her and would travel from afar to continue care with her. A patient's wife wrote: "We miss 
her...she was such a joy. We loved her caring way and her big smile. We would always stop at Casa De Fruta on our way to see her from Bakersfield (250 miles from Palo Alto) and bring her fresh fruit, which would really make her smile. She would spend a good hour with my husband listening to his many concerns and reassuring him. She was just awesome!" In 2009, the Board of Stanford Hospital and Clinics recognized her clinical excellence and patient advocacy with the Denise O'Leary Award.

Cristanne received numerous awards for her teaching skills throughout her career. As a resident she received the best medical student teaching award at Boston University School of Medicine, "Vaandragerprijs" award for exceptional teaching skills by the Dutch society of neurology residents, and the Dr. Lysia Forno Award for teaching excellence from the Stanford neurology residents. She was generous with her knowledge, time, skills, and her wisdom to her students and peers. She was an inspiration and a role model for all physician educators.

While internationally recognized for her contributions to the advancement of stroke and neurocritical care research, many of us remember her for her larger-than-life personality, her infectious and exuberant laughter, her friendship, her passion for life and her love for singing and dancing. During her treatment for breast cancer in 2010, she founded and performed as the lead singer for a Stanford neurology band, the HyperTonics. Cristanne said, "I was always someone who loved to dance and sing, and I could keep a tune." The HyperTonics performed at several neurology conferences in the United States along with Bubba's Taxi (UCSF) and the Codes (Columbia). We still recall her exhilaration and happiness the week(s) after the band's first performance in San Francisco.

Cristanne is survived by her devoted husband, Dr. David Reitman, her two children, Fred (14) and Anna (12), her sister, Dr. Marjolein Wijman-Schulten, and her brother, Gert-Jan Wijman. Her memorial card on March 8, 2013, read, "Her presence in the lives of all those she touched will be sorely missed and never replaced. May she rest in peace." She was truly one of a kind. She will be missed. 